\title{
Colliding Worlds: An Aging Workforce, Artificial Intelligence, and the Impact on the Future of Work
}

By Renée McGowan and Natalie Corrado

\footnotetext{
ust like the world around us, the way we work is changing rapidly. A myriad of changes are impacting the way we live, work, and retire: rapid globalization; the growth of middle-class populations; issues of gender, diversity, and inclusion; aging; technology; and new ways of working in the gig economy. Two trends, however, are unprecedented in their scope: widespread societal aging and the automation of work by intelligent technologies. Increased life expectancies and decreasing birth rates across the world mean working-age populations are shrinking in many major countries. In Japan, the proportion of the working-age population ages 50-64 is expected to reach 38 percent by 2030, while in the United Kingdom, the only growing labor pool is among those over 50 . The rate and scale of automation is also increasing, with advances in machine learning impacting the way the world works and the skills required in the workforce. The confluence of these two trends will have a profound impact on the future of work, particularly for older working populations.
}

As automation increasingly enables unprecedented levels of productivity, the capacity of organizations to invest in new revenue streams and new economies will expand. Investing in younger workers will become increasingly difficult as young populations shrink, but older workers in aging nations are increasingly willing and able to engage in meaningful work. The idea of retiring at 65 and completely exiting the workforce is no longer our reality. Several notable socioeconomic trends are at play making older workers more willing and able to work:

1. Financial motivation: Retirement savings gaps are widening dramatically throughout the world due to longer life expectancies and inadequate retirement savings programs. Mercer's analysis of this phenomenon shows this gap is now at more than $\$ 70$ trillion globally, and, based on a 5 percent average annual growth rate, is projected to reach $\$ 400$ trillion by $2050^{1}$. The average pension gap in Europe for women is about 40 percent $^{2}$, and it is particularly severe for women in
Asia due to both the gender wage gap and the fact that, on average, women spend less time in the workforce than men. These wide gaps are a powerful motivation for older workers returning to or remaining in the workforce.

2. Personal motivation: While financial reasons are the most common motivation, older workers also frequently cite numerous nonfinancial reasons for remaining in and returning to the workforce, such as the desire to stay healthy, active, and connected, and finding self-fulfillment in their work ${ }^{3}$. In their widely acclaimed book, The 100 Year Life, professors Lynda Gratton and Andrew Scott cite survey results showing nearly 60 percent of workers ages 45 and older investing in new skills for work, and the majority of them reporting they were positive and excited about their jobs. Developments in health care and education levels over the past century have clearly increased older workers' propensity for extending their working lives. 


\section{"Older workers are indeed becoming more} willing and able to engage in meaningful work, and companies would do well to incorporate older workers into their future strategies."

As firms prepare themselves for uncertain times ahead, it is crucial they plan for these demographic changes as well. Older workers are indeed becoming more willing and able to engage in meaningful work, and companies would do well to incorporate older workers into their future strategies.

Mercer's latest report, The Twin Threats of Aging and Automation, assessed the effect increased workplace automation will have on older worker populations, including exploration of the differences in automation across developed countries (see chart). Studies show there is also a high association between higher rates of aging and higher rates of automation, supporting the notion that shrinking prime-age working populations push firms to seek alternative sources of productivity beyond local labor, such as automation ${ }^{4}$. An appreciation of these relationships is crucial to understanding older workers' place in the labor market.

However, as we move toward higher levels of technological achievement, technology will be designed with humans at the center, making it more and more humane. In the future, work will be less about using technology (which implies a technical skill), and more about interacting with technology (which implies interpersonal skills). Put another way, technical skills become the means by which to compete and human skills become a competitive advantage.

The spread of automation will therefore require human beings and human skills to play an even bigger role in reorganizations. What in the past was considered premium will now be considered standard, a phenomenon that will necessarily push human workers out from lower-value labor in to more value-added services. For example, plant and machine operators could become specialty technicians and robotics supervisors. Companies, therefore, have much to benefit from by investing in the productivity gains from automation in their human workers, particularly older ones.

It is also important to note that older workers can be a treasure trove of experience, adaptability, and productivity given the right environment and opportunities. Researchers have found, for example, that older workers tend to outperform younger workers in semantic 


\section{FINANCIAL RESILIENCE}

\section{Association of Aging and Automation}

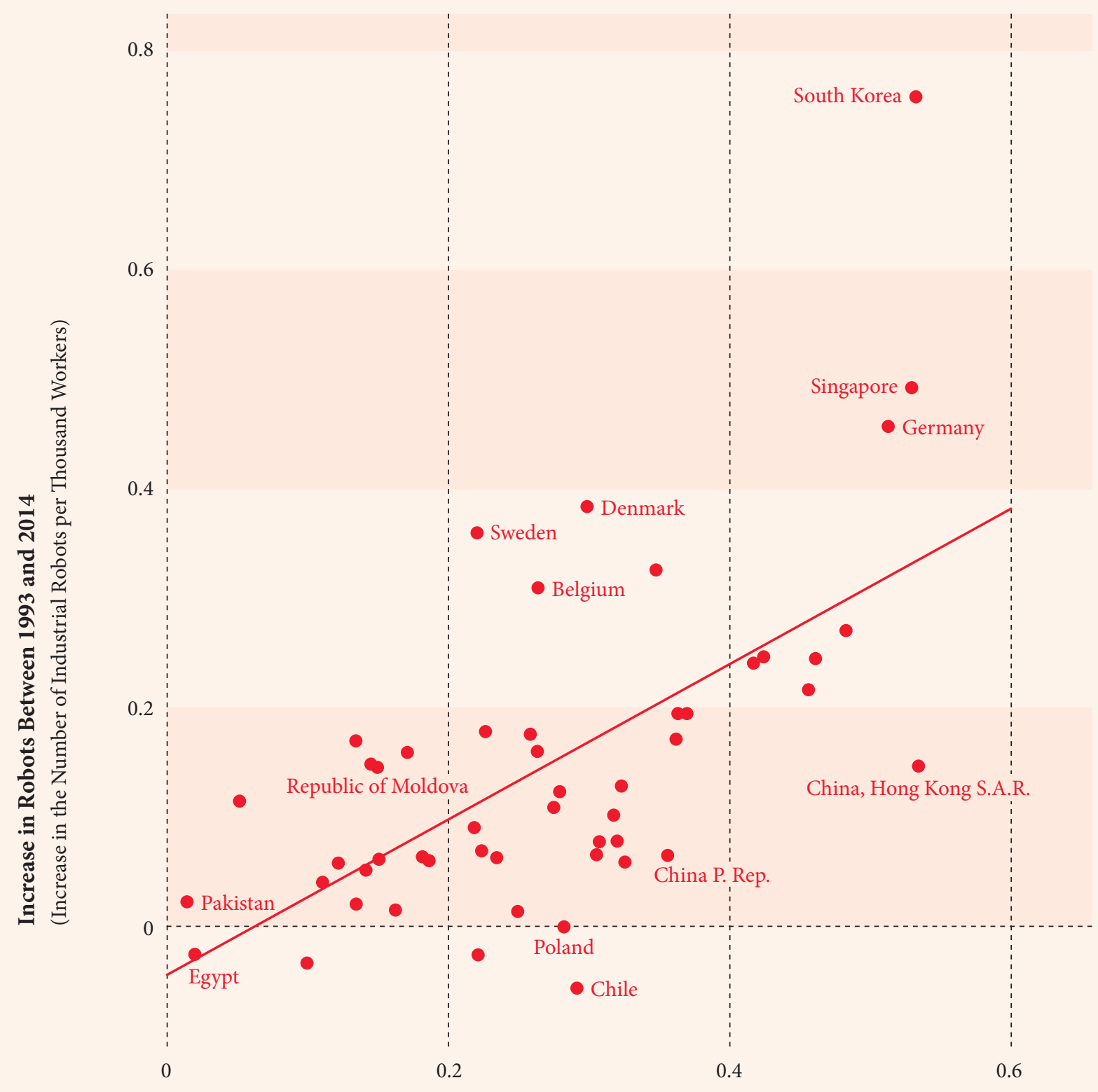

Aging Between 1990 and 2025

(Change in the Ratio of Workers Above 56 to Workers Ages 21-55) 
memory and language and speech skills. Older workers also provide critical abilities for firm building, knowledge consolidation, and continuity in times of flux. An age-diverse workforce can even reduce costs by increasing organizational commitment and reducing turnover. ${ }^{5}$

While an age-diverse workforce can lower costs, the rise of new technologies means that the human workforce will need to evolve rapidly to keep pace. In fact, the World Economic Forum's Future of Jobs report ${ }^{6}$ warns that only 35 percent of today's skills will be applicable in 2020. Further, today's transition to a workforce of the future will require low- and basic-skilled workers to face a far steeper learning curve to remain productive. This learning curve will be particularly challenging for older workers as strong problem solving skills are needed in the computer and software fields. As a result, an additional societal cost is at play here that will need to be shared by firms and governments: that of education and training that focuses on older workers.

With more and more older people reentering and remaining in the workforce around the world, concerted efforts on the part of companies and governments for encouraging and accommodating the older worker will be crucial in the coming decades. Investing in older workers through firm retaining programs and older worker accommodation strategies would help older workers reskill and be redeployed in the workplace, and provide firms with a fresh source of vitality in a world of shrinking young labor forces. Technology developments and the automation of work offer companies a unique opportunity to evolve and upgrade their suite of offerings. With labor markets around the world aging so rapidly, firms will be required to use the unique abilities of older workers as part of this evolution. This underscores the need for a widespread change in how we think about the future of work and ensuring older workers have a role in this journey toward building a workforce for the future.

1. World Economic Forum, "We'll Live to 100 - Can we Afford It?"; Mercer analysis (weforum.org, World Economic Forum, 2017).

2. European Parliament, "Gender Gap in Pensions: Looking Ahead"; Citizen's Rights and Constitutional Affairs Policy Department (europarl.europa.edu, European Parliament, 2017).

3. European Commission, "Employment of Older Workers"; The Centre of Aging \& Work at Boston College, "Older Workers: What Keeps Them Working?" (dlib.bc.edu, Marcie Pitt-Catsouphes \& Michael A. Smyer, 2005).

4. UN World Population Prospects, "Change in Percentage of Total Population Age 65+ Between 2015-2050"; International Federation of Robotics, IFR World Robotics Report 2017 (esa.un.org, International Federation of Robotics, 2017).

5. Robert L. Lord \& Phillip A Farrington, "Age-Related Differences in the Motivation of Knowledge Workers" (Engineering Management Journal, 18:3, 20-26, 2006).

6. World Economic Forum, The Future of Jobs Report (reports.weforum.org, World Economic Forum, 2016).

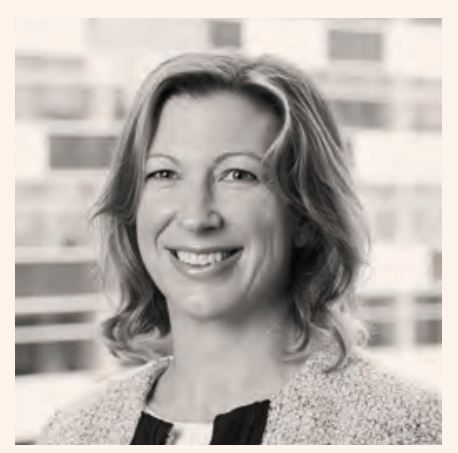

Renée McGowan CEO, ASIA, MERCER

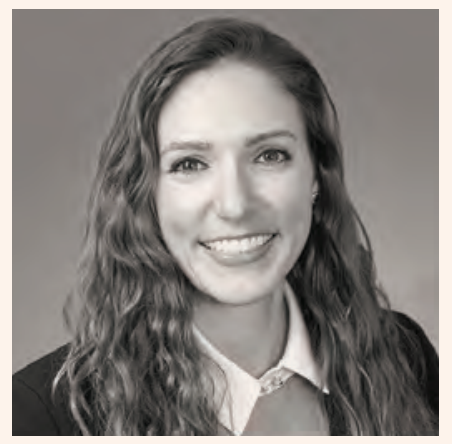

Natalie Corrado GLOBAL BUSINESS STRATEGY MANAGER FOR INDIVIDUAL WEALTH, MERCER 